\title{
The Effect of Plastomers Polymer Type and Concentration on Asphalt and Moisture Damage of SMA Mixtures
}

\author{
Al-Hadidy $\mathrm{AI}^{1}$ and Tan Yi-qiu ${ }^{2}$ \\ ${ }^{1}$ Lecturer, College of Engineering, Civil Dept., Mosul University, Mosul-Iraq, \\ ${ }^{2}$ Prof. of School of Transportation Science and Engineering, (HIT), China
}

\begin{abstract}
In this investigation, two plastomers polymer types namely: polyethylene (PE) and polypropylene (PP) were used to modify asphalt cement. Nine different blends including conventional mixture were subjected to binder testing such as rheological tests before and after aging, as well as to some other tests related to the uniformity of the system. Marshall stability, Marshall Quotient, static tensile strength, tensile strength ratio, static compressive strength and index of retained strength were carried out on the stone mastic asphalt (SMA) mixtures. Research results indicate that the addition of these polymers enhance the unaged and aged rheological properties of base binder. The results also indicated that the modified binders are complying with the ASTM D491 specifications for asphalt used in waterproofing applications. As well as, the SMA mixtures containing such binders can satisfy the performance requirement of hightemperature and much rain zone.
\end{abstract}

Keywords: Asphalt cement; Binders; Plastomers polymer; Rheological tests; Moisture damage; Stone mastic asphalt.

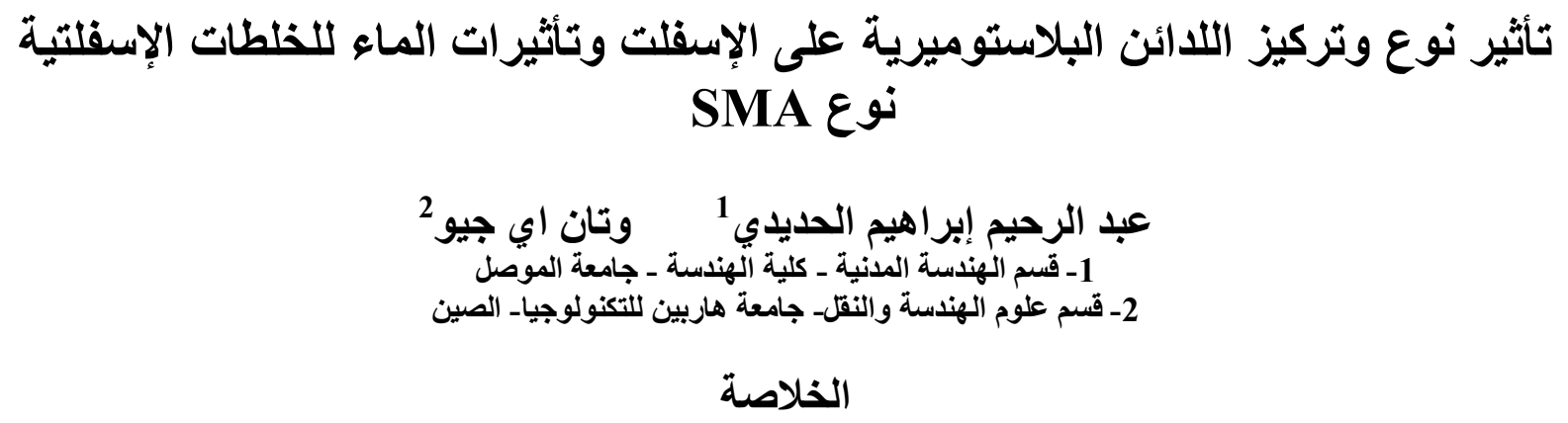

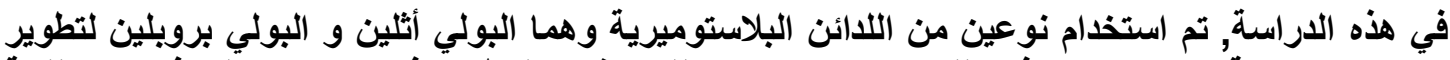

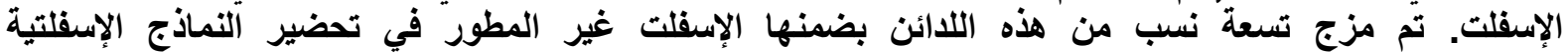

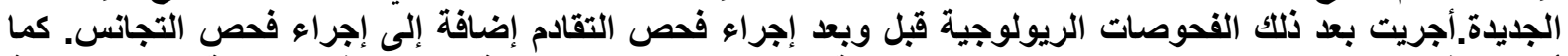

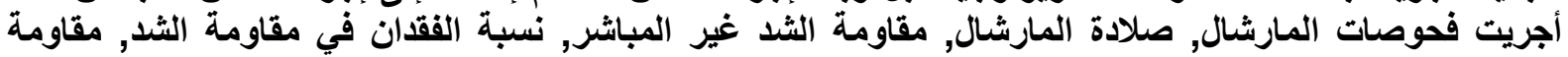

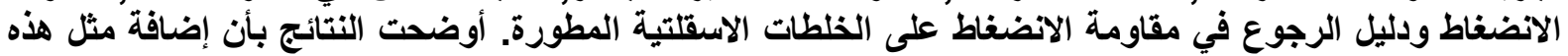

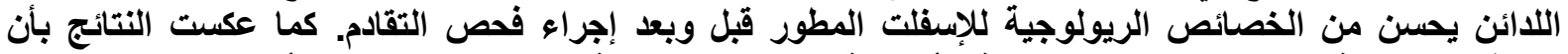

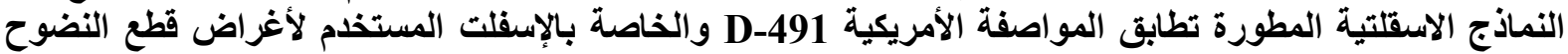

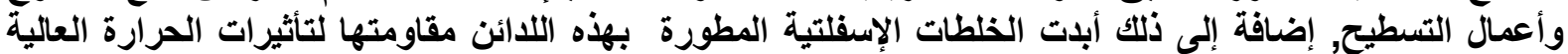

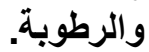
الكلمات الدالة:الإسفلت, المادة الرابطة ، اللدائن البلاستوميرية، الفحوصات الريولوجية، تأثير الرطوبة, SMA. 


\section{INTRODUCTION}

Environmental factors such as temperature, air, and water can have a profound effect on the durability of asphalt concrete mixtures. In mild climatic conditions where good-quality aggregates and asphalt cement are available, the major contribution to the deterioration may be traffic loading, and the resultant distress manifests as fatigue cracking, rutting (permanent deformation), and raveling [1]. However, when a severe climate is in question, these stresses increase with poor materials, under inadequate control, with traffic as well as with water which are key elements in the degradation of asphalt concrete pavements. Water causes loss of adhesion at the bitumen-aggregate interface. This premature failure of adhesion is commonly referred to as stripping in asphalt concrete pavements [2, 3 and 4]. The strength is impaired since the mixture ceases to act as a coherent structural unit. Loss of adhesion renders cohesive resistance of the interstitial bitumen body useless.

Water may enter the interface through diffusion across bitumen films and access directly in partially coated aggregate [5]. Water can cause stripping in five different mechanisms such as detachment, displacement, spontaneous emulsification, pore pressure, and hydraulic scour $[1,3,6]$.

Many variables affect the amount of moisture damage which occurs in an asphalt concrete mixture. Some of these variables are related to the materials forming hot mix asphalt (HMA) such as aggregate (physical characteristics, composition, dust, and clay coatings) and bitumen (chemical composition, grade, hardness, crude source, and refining process). Others are related to mixture design and construction (air void level, film thickness, permeability, and drainage), environmental factors (temperature, pavement age, freeze-thaw cycles, and presence of ions in the water), traffic conditions and type, and properties of the additives [5].

To alleviate or to control the deformations due to water damage, various researches were performed leading to the utilization of anti-stripping additives [7]. Anti-stripping additives are used to increase physico-chemical bond between the bitumen and aggregate and to improve wetting by lowering the surface tension of the bitumen [8]. The additives that are used in practice or tested in the laboratory include: (i) traditional liquid additives, (ii) metal ion surfactants, (iii) hydrated lime and quick lime, (iv) silane coupling agents, and (v) silicone [5].

Among them, hydrated lime and quicklime are the most commonly used solid type antistripping agents $[9,10,11$ and 12]. There are five methods for introducing hydrated lime into HMA [11, 13, 14, 15, 16, 17 and 18]. These are: (i) lime slurry to dry or wet aggregate, (ii) dry lime to wet aggregate, (iii) dry lime to dry aggregate (iv) dry lime to bitumen, and (v) quicklime slurry to dry or wet aggregate.

Methods of treatment to reduce moisture damage also include the utilization of polymer modified bitumen [19, 20 and 21]. Although, the utilization of polymer modified binders (PMBs) for controlling the moisture damage is limited, there is evidence that some polymers can act as anti-stripping agents [17].

Kim et al. reported that, polymer modified systems could accommodate more damage prior to failure that of unmodified systems. They indicated that mixtures containing PMB strongly exhibited less moisture damage [22]. 
Kumar et al. set out to examine the strength characteristics of polymer modified mixes. In their studies they concluded that there was an improvement in the moisture susceptibility characteristics of the polymer modified mixes [23].

Stuart et al. reported that, mixtures with PMBs exhibited greater resistance to moisture damage than the mixtures with unmodified bitumen by providing increased adhesion to the aggregate and by creating a network within the bitumen [24].

The aims of this paper are: (1) to determine the unaged and aged properties of plastomers PMBs; (2) to find out if such binders can be used as waterproofing materials (asphalt mastic); (3) to determine Marshall properties, Marshall Quotient (resistance to deformation), static indirect tensile and compressive strength at 25 and $60^{\circ} \mathrm{C}$, and moisture susceptibility of plastomers polymer modified stone mastic asphalt (PMSMA) and compare with control SMA; and (4) to find the most promising test of stripping for SMA mixtures among the static indirect tensile and compressive strength.

\section{MATERIALS AND METHODS Materials Used}

Asphalt cement of 50/60-penetration grade was used as a base binder. PMB of 50 grades (PMB-50) with PE and PP at different concentrations was used in this investigation. For the modification of base binder, the amounts of PE concentration by mass of asphalt are $2 \%$ up to $8 \%$, whereas for PP between $1 \%$ and $7 \%$. PE and PP copolymer in solid form was mixed at $170^{\circ} \mathrm{C}$ using a high-speed stirrer rotating at a speed of $3000 \mathrm{rpm}$, and blending was done for a period of $2 \mathrm{~h}$ to obtain a homogeneous binder $[25,26]$. The uniformity of dispersion of $\mathrm{PE}$ and PP was confirmed by passing the bitumen at $170^{\circ} \mathrm{C}$ through an ASTM 100 sieve. It was found that the binder thus prepared can be stored for future use [27]. Eight types of binders namely: PE2MB, PE4MB, PE6MB, PE8MB, PP1MB, PP3MB, PP5MB and PP7MB were thus prepared. The number after polymer type was subset to represent its concentration.

Aggregate was obtained from one asphalt plant in Heilongjiang province located in the north part of China. Figure 1 shows the recommended gradation limits by the SC DOT [28] for SMA mixtures and the selected gradation in this research was in the middle of the limits. The properties of the aggregates, such as angularity value, toughness value, soundness value, water absorption value, and specific gravities were determined, and the test results are presented in Table 1.

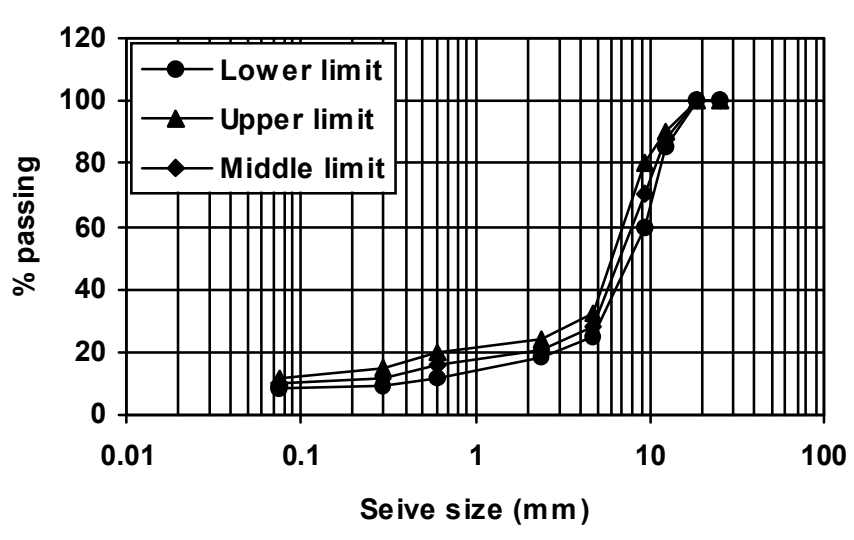

Figure 1. SMA gradation limits

The filler used was calcium carbonate $(\mathrm{CaCO} 3)$ and it was brought from one asphalt plant. Calcium carbonate was passed through a 200 sieve and had specific gravity of 2.734 . 
Table 1. Source and consensus properties of aggregates

\begin{tabular}{|cccc|}
\hline & Coarse & Fine & Test Method \\
Property & Aggregate & Aggregate & ASTM) \\
Bulk sp.gr. & 2.721 & 2.652 & C-127 \& C- \\
Apparent sp.gr. & 2.763 & 2.691 & 128 \\
water absorption, $\%$ & 0.278 & 1.4877 & \\
Angularity, $\%$ & $>100$ & 44.863 & \\
Toughness, $\%$ & 22.07 & ---- & $\mathrm{C}-131$ \\
Soundness, $\%, \mathrm{Na}_{2} \mathrm{SO}_{4}$ & 1.784 & 1.205 & C-88 \\
\hline
\end{tabular}

\section{Mixture Design}

The mix design procedure for SMA as proposed in NCHRP report No.425 [29] was followed in performing the mix design to be used. The tested materials that meet the normal SMA specifications were used to produce the mixes without mineral fiber. Laboratory specimens were prepared using fifty blows of the Marshall hammer per side. Seventy-five compaction blows were not used since they would not result in a significant increase in density over that provided by 50 blows. SMA mixtures have been more easily compacted on the roadway to the desired density than the effort required for conventional HMA mixtures [30]. The optimum asphalt content for SMA mixtures is usually selected to produce $4 \%$ air voids and drain down of less than $0.3 \%$.

In this research, compaction of all the SMA samples was performed using fifty blows of the Marshall hammer per side. The optimum binder content for the control mixture was found to be $6 \%$ at $4 \%$ air voids, and it was used in preparing all other mixtures to maintain consistency through the study. Five identical samples for each mixture were fabricated.

\section{Performance Tests Used}

Two performance tests in the laboratory were adopted. The tests performed were moisture susceptibility and Marshall Quotient (resistance to deformation) tests. The moisture susceptibility test was studied using the tensile strength ratio (TSR) and index of retained strength (IRS) according to ASTM. Procedures were performed on the nine SMA mixes, which were compacted to an average air void content of $7.0 \%$. Five Marshall specimens for the unconditioned group and five specimens for the conditioned group were prepared. A TSR and IRS of conditioned group to unconditioned group were computed from the results of the indirect tensile and compressive strength tests at $25^{\circ} \mathrm{C}$. The higher the TSR or IRS value, the less the strength should be influenced by the water soaking condition, or the more water-resistant it should be. SMA specification according to SCDOT [28] requires a TSR and conditioned tensile strength values of $85 \%$ or more and $448 \mathrm{kPa}$, respectively.

\section{RESULTS AND DISCUSSION Statistical Considerations}

Results of the drain down, Marshall, indirect tensile strength, tensile strength ratio, compressive strength and index of retained strength tests were statistically analyzed with a 5\% level of significance using SPSS statistical analysis program V.16. For these comparisons, it should be noted that all specimens were produced at optimum binder content. 


\section{Basic Properties Of PMBS}

The basic properties of the unaged and aged PMBs were evaluated and the results are presented in Figure 2. Basic test properties indicated that the addition of PE and PP content to base binder reduces the penetration, ductility and percentage loss of heat values, whereas increases in softening point and aging index (the ratio of penetration of residue to that of original binder) values were observed with the addition of PE and PP modifiers. The study showed that the softening point values for PE6MB and PP5MB were higher by $26 \%$ and $21 \%$, whereas the penetration and loss of heat values were found to be lower by $45 \%$ and $41 \%$, and $24 \%$ and $31 \%$, respectively, when compared to base binder. The results also, revealed that all $\mathrm{PE}$ and $\mathrm{PP}$ contents kept the ductility values at a minimum range of ASTM specifications of $100+$, which indicates that PE and PP are completely dissolved in base binder. The increasing in softening point and the reduction in penetration values of base binder with the addition of PE and PP modifiers can be attributed to the harder consistency of PE and PP-asphalt binders. The reduction in percentage loss due to heat and air (Thin Film Oven Test, TFOT) related to that PE and PP occupied a space of total mix and causes reduction in asphalt volume, which leads to a decrease in loss by dehydrogenation and oxidation of asphalt in the mix (i.e. durability increased slightly with the addition of PE and PP content in the mix).

The temperature susceptibility of asphalt binders is quantified by penetration index (PI). Calculated values of PI for PMBs and asphalt cement are given in Figures $2 \mathrm{f}$. A higher value of PI indicates the lower temperature susceptibility of binder. From this Figure, it can be observed that the values of P.I. for asphalt, PE4MB, PE6MB, PP3MB and PP5MB samples are $-0.547,0.515,0.809,-0.017$ and 0.519 , respectively. This significant fact demonstrates that PE and PP will lead to make this binder less susceptible to temperature and more favorable for hot climates.

Examining Figure 2, it can be seen that the physical properties of PE4MB, PE6MB, PE8MB, PP3MB, PP5MB and PP7MB including softening point, penetration, ductility and loss of heat are complies with the ASTM D491 specifications for asphalt used in waterproofing (asphalt mastic). Such binders are suitable for exterior below-grade or between-slab applications. It recommended for: Parking garages and concrete tanks, plaza decks and malls, fountains and pools, balconies and planters, bridges and highways, below-grade slabs, walls and culverts, sea walls, dams and reservoirs, etc.

\section{Drain Down}

Drain down test using wire basket method as proposed in the NCHRP Report No.425 [29] was run on all the mixes evaluated. In this test, the laboratory-prepared loose mix was placed in a forced draft oven for $1 \mathrm{~h}$ at a pre-selected temperature. At the end of $1 \mathrm{~h}$, the basket containing the sample is removed from the oven along with the plate and the mass of the plate was determined. The amount of increased weight of the plate is the amount of drain-down of the mix. As specified in NCHRP [29], the oven temperature for performing the drain down test should be at the mixing temperature and/or the mixing temperature plus $15^{\circ} \mathrm{C}$. Thus, an oven temperature of $150^{\circ} \mathrm{C}$ was used for the control mixture and an oven temperature of $165^{\circ} \mathrm{C}$ was used for the other modified mixtures. All the SMA mixtures in this study passed the drain down test. 


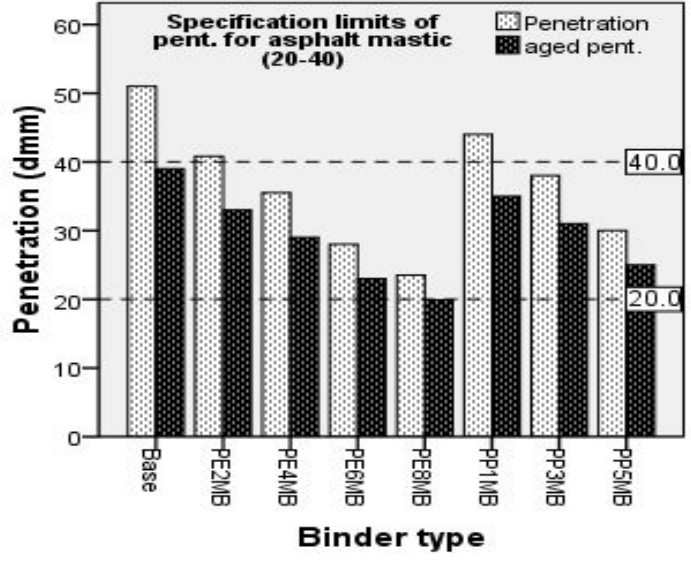

(a)

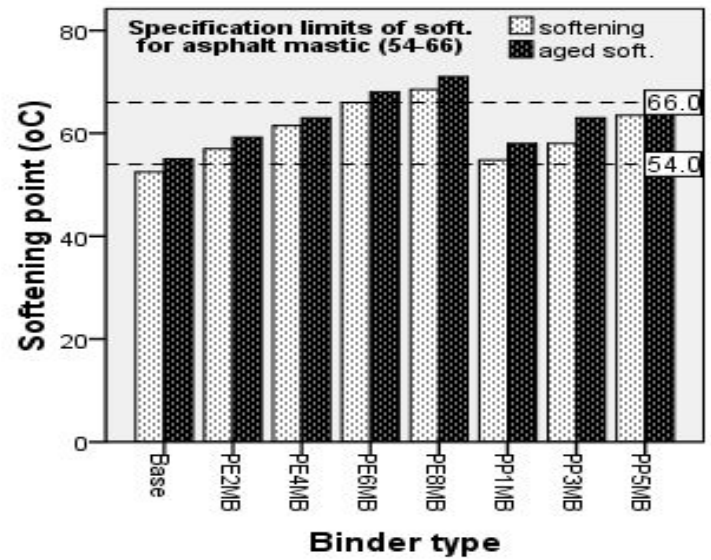

(c)

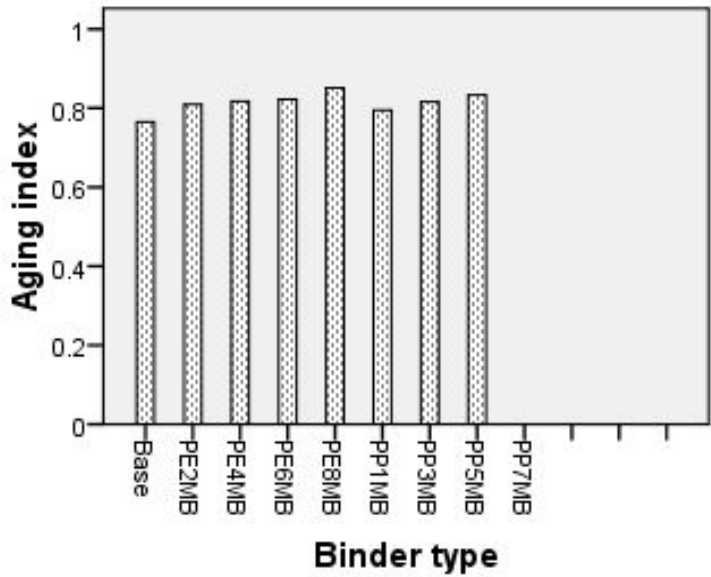

(e)

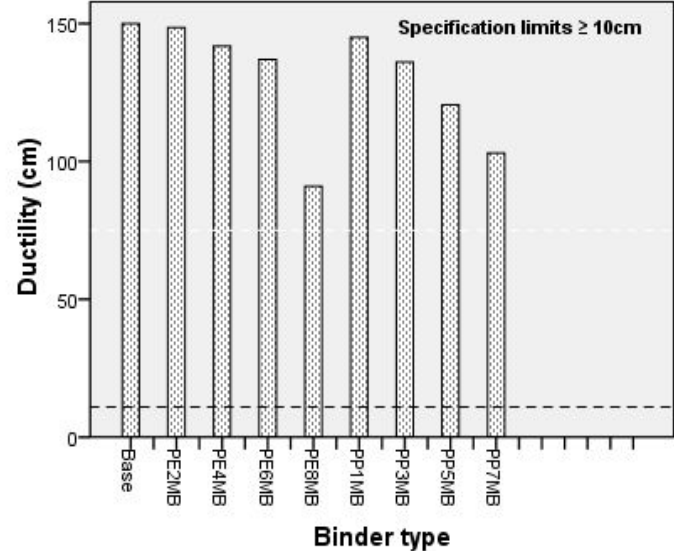

(b)

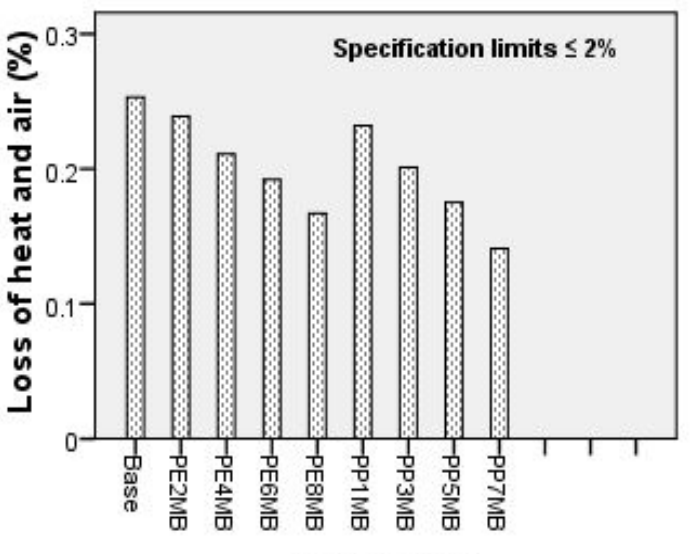

Binder type

(d)

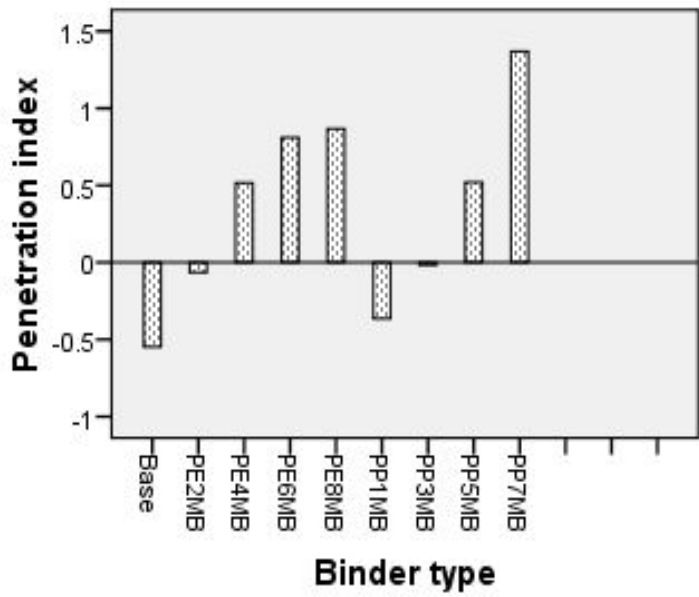

(f)

Figure 2. Basic properties of PMBs

Figure 3 shows the drain down test results for the SMA mixtures. From Figure 3, it can be observed that the PE4MB, PE6MB, PP3MB and PP5MB reduced the drain down 
values for the control SMA mixture by $9 \%$, $17 \%, 8 \%$ and $20 \%$, respectively. No fiber was needed to prevent drain-down when these binders were used.

\section{Marshall Properties}

The Marshall properties of SMA mixtures were evaluated and the results are presented in Figure 4. From this Figure, it can be seen that the PE4MB, PE6MB, PP3MB and PP5MB raised the Marshall stability and Marshall Quotient (MQ) of the control SMA mixture by $49 \%, 55 \%, 25 \%$ and $46 \%$, and $68 \%, 80 \%$, $36 \%$ and $69 \%$, respectively. It can be said that

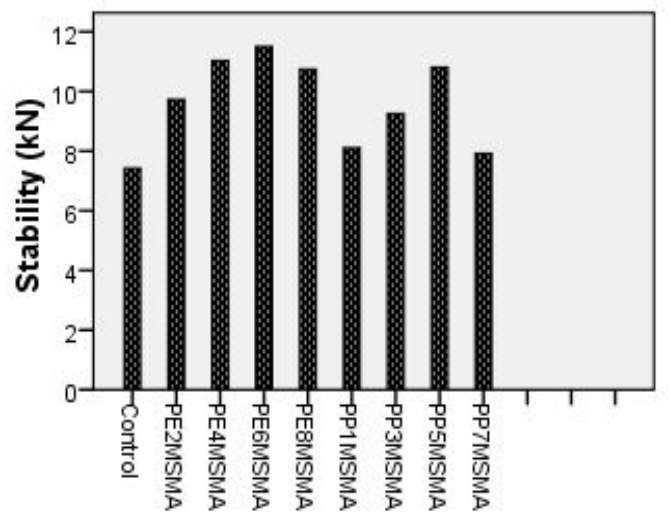

Mixture type

(a)

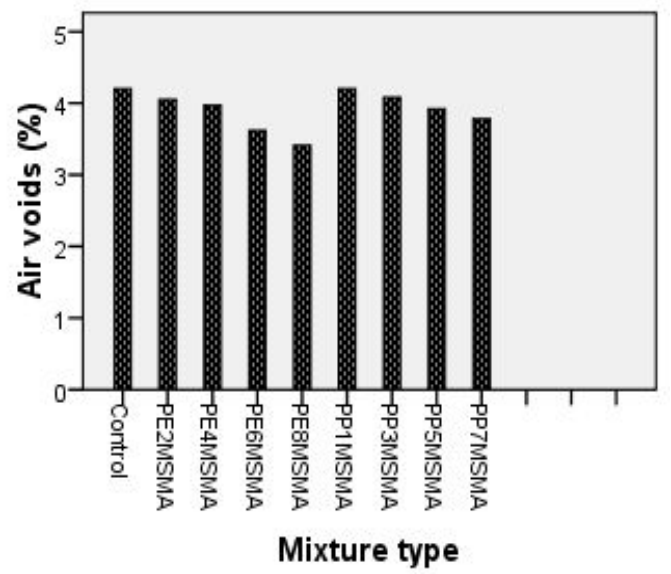

(c)

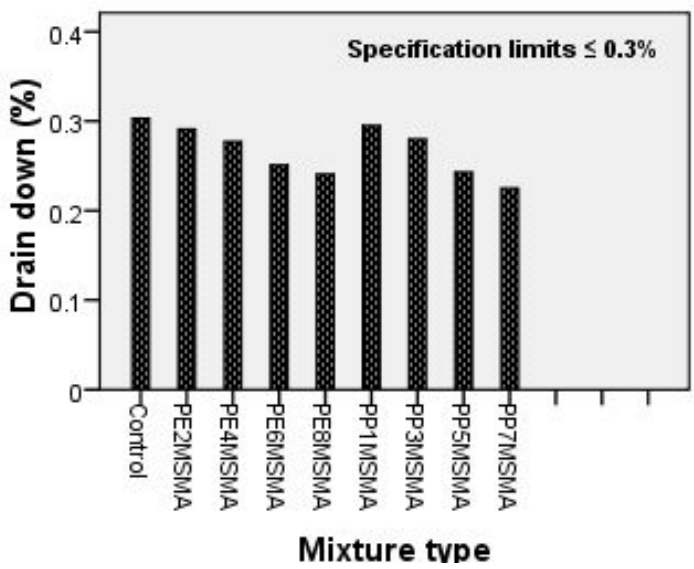

Figure 3. Drain down of the

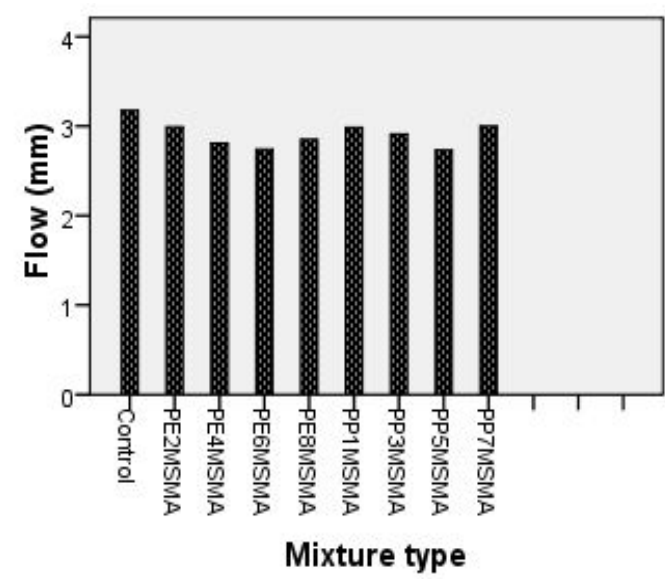

(b)

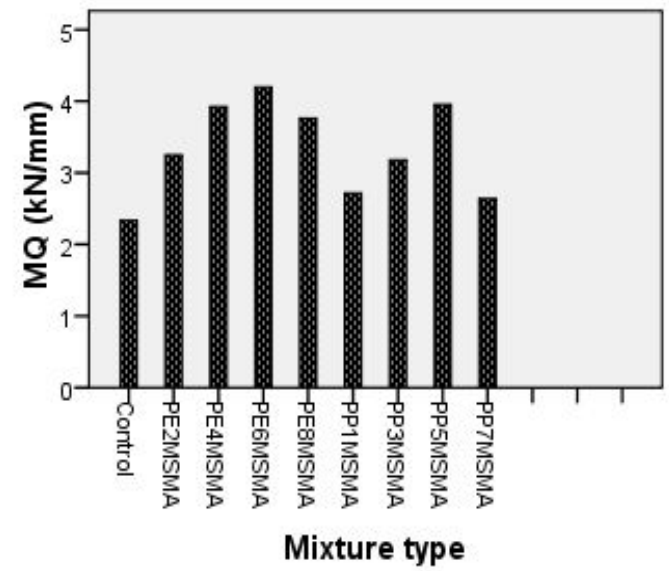

(d)

Figure 4. Marshall test results of the mixtures (a- Stability, b- Flow, c- MQ \& d- Air voids) 
these binders provide better resistance against permanent deformations due to their high stability and high MQ and indicate that PMSMA mixtures could be use in military airfield pavements where stiff asphalt mixture and low asphalt content are required.

The sited results in Figure 4 also revealed that all SMA mixtures satisfy the air voids and flow specif of $3-5 \%$ and $2-5 \mathrm{~mm}$, respectively.

\section{Moisture Susceptibility}

Tensile strength and TSR for the mixtures are given in Figure 5 and 6, respectively.

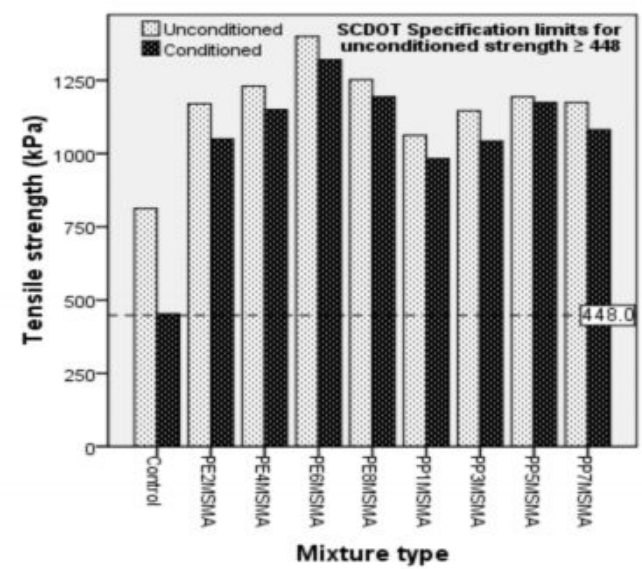

Figure 5. Tensile strength of the mixtures

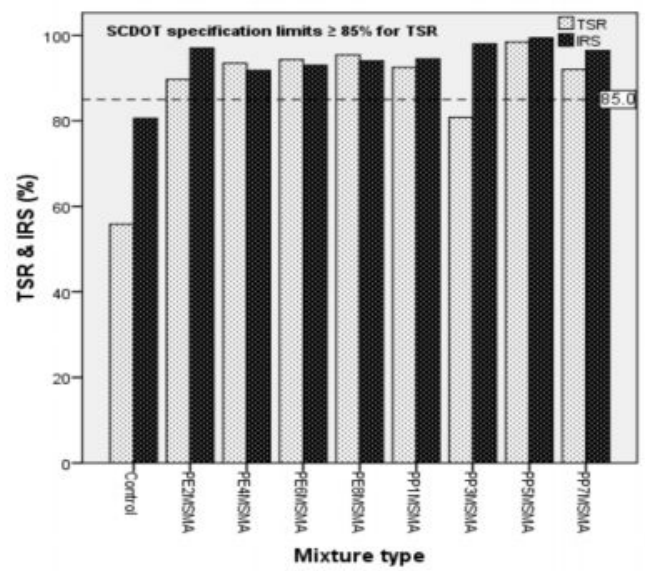

Figure 6. TSR and IRS of the mixtures

For control, PE4MSMA, PE6MSMA, PP3MSMA and PP5MSMA mixtures, average static indirect tensile strength values of the conditioned specimens are $453 \mathrm{kPa}, 1150 \mathrm{kPa}$, $1320 \mathrm{kPa}, 1042 \mathrm{kPa}$ and $1174 \mathrm{kPa}$, respectively. For these, coefficient of variations $(\mathrm{COV})$ of results observed were $1 \%, 6.6 \%, 4.7 \%, 3.6 \%$ and $2 \%$, respectively. Average static indirect tensile strength values obtained for unconditioned specimens are $812 \mathrm{kPa}$, $1230 \mathrm{kPa}, 1400 \mathrm{kPa}, 1146 \mathrm{kPa}$ and $1194 \mathrm{kPa}$, respectively. For these, $\mathrm{COV}$ of results observed were $4.2 \%, 3.8 \%, 5.9 \%, 1 \%$, and $5.8 \%$, respectively. From these, values \% TSR obtained for control, PE4MSMA, PE6MSMA, PP3MSMA and PP5MSMA mixtures are 56\%, 94\%, 94\%, $81 \%$ and $98 \%$, respectively.

Figure 6 and 7 show IRS and the compressive strength for the mixtures. For control, PE4MSMA, PE6MSMA, PP3MSMA and PP5MSMA mixtures, average static compressive strength values of the conditioned specimens are $4082 \mathrm{kPa}, 5700 \mathrm{kPa}, 6510 \mathrm{kPa}, 5628 \mathrm{kPa}$ and $6090 \mathrm{kPa}$, respectively. For these, COV of results observed were $1.9 \%, 2.1 \%, 1 \%, 2.2 \%$ and $1.5 \%$, respectively. Average static indirect tensile strength values obtained for unconditioned specimens are $5066 \mathrm{kPa}, 6210 \mathrm{kPa}, 7000 \mathrm{kPa}$,

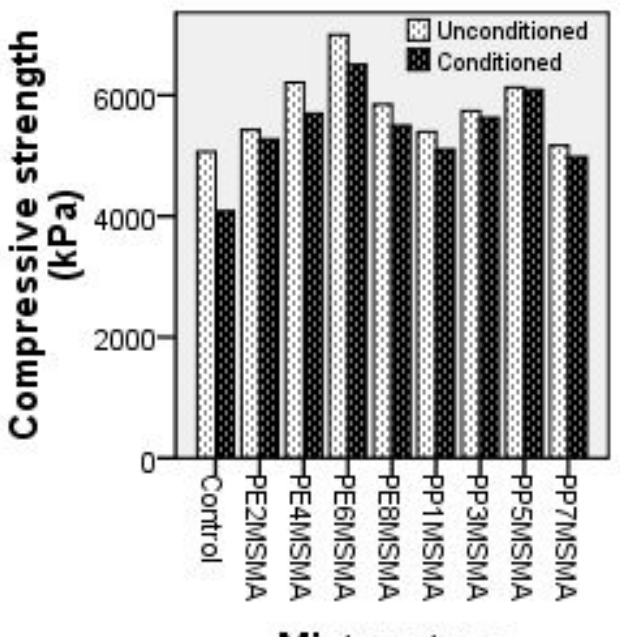

Figure 7. Compressive strength of the mixture 
$5742 \mathrm{kPa}$ and $6128 \mathrm{kPa}$, respectively. For these, COV of results observed were $4.3 \% 2$, $3.3 \%, 2.7 \%, 2.3 \%$ and $2 \%$, respectively. From these, values $\%$ IRS obtained for control, PE4MSMA, PE6MSMA, PP3MSMA and PP5MSMA mixtures are 81\%, 92\%, 63\%, 98\% and $99 \%$, respectively. These results revealed that the indirect tensile strength test was the most promising of stripping when applied to SMA paving mixtures.

Hence, it should be mentioned that PMBs up to $6 \%$ of PE and $5 \%$ of PP were discussed herein, so these percentages comply with polymer loaded in concentrations of about $4-6 \%$ by weight with respect to the asphalt as mentioned by [20]. Also, higher concentrations of polymers are considered to be economically less viable and also may cause other problems related to the material properties.

\section{CONCLUSIONS}

From the types of materials used and within the limitation of tests in this study, the following conclusions can be drawn:

1. Unaged and aged penetration at $25{ }^{\circ} \mathrm{C}$ will generally decrease as plastomers polymer concentration increases, which indicates an improved shear resistance in medium to high temperatures.

2. The addition of plastomers polymers kept the unaged ductility values at a minimum range of ASTM specifications of 100+.

3. Softening point before and after aging tends to increase with the addition of plastomers polymer, which indicates improvement in resistance to deformation and the MQ value insure these results.

4. The percentage loss of air and heat decreases with the addition of plastomers (i.e. the resistance of base binder to the action of temperature and temperature changes and the action of heat increases).

5. The uniformity test using an ASTM 100 sieve indicates that the prepared plastomers polymer-asphalt can be stored for future use.

6. Penetration index values indicated that plastomers polymer reduced the temperature susceptibility of asphalt cement.

7. The unaged and aged physical properties of PE4MB, PE6MB, PE8MB, PP3MB, PP5MB and PP7MB including softening point, penetration, ductility and loss of heat are complies with the ASTM D491 specifications for asphalt used in waterproofing (asphalt mastic).

8. The PE4MB, PE6MB, PP3MB and PP5MB reduced the drain down values for the control SMA mixture by $9 \%, 17 \%, 8 \%$ and $20 \%$, respectively. No fiber was needed to prevent drain-down when these binders were used.

9. The PE4MB, PE6MB, PP3MB and PP5MB raised the Marshall stability and MQ of the control SMA mixture by $49 \%, 55 \%, 25 \%$ and $46 \%$, and $68 \%, 80 \%, 36 \%$ and $69 \%$, respectively. It can be said that these binders provide better resistance against permanent deformations due to their high stability and high MQ., and;

10. The control mixtures show $56 \%, 94 \%, 94 \%, 81 \%$ and $98 \%$ higher tensile strength ratio, and $81 \%, 92 \%, 63 \%, 98 \%$ and $99 \%$ higher index of retained strength ratio with the utilization of PE4MB, PE6MB, PP3MB and PP5MB, respectively. These indicate that moisture susceptibility of PE4MSMA, PE6MSMA, PP3MSMA and PP5MSMA mixtures is lower when compared to control mixture 


\section{REFERENCES}

[1] Cagri Gorkem, Burak Sengoz: Predicting stripping and moisture induced damage of asphalt concrete prepared with polymer modified bitumen and hydrated lime. J Constr Eng Build Mater 2009; XXX(X).

[2] Fromm HJ. Mechanism of asphalt stripping from aggregate surfaces. AAPT 1974;43:191-223.

[3] Taylor MA. Khosla NP. Stripping of Asphalt Pavements: State of the Art, Transportation Research Record 911, TRB, National Research Council, Washington (DC); 1983. p. 150-8.

[4] Kandal PS, Lubold CW, Roberts FL. Water damage to asphalt overlays: case histories. AAPT 1989;58:40-76.

[5] Stuart KD. Moisture damage in asphalt mixtures: a state of art report. Research Development and Technology, Turner-Fairbank Highway Research Center, 1990.

[6] Kiggundu BM, Roberts FL. The success/failure of methods used to predict the stripping potential in the performance of bituminous pavement mixtures. Auburn University: National Center for Asphalt Technology, 1988.

[7] Hunter ER. Evaluating moisture susceptibility of asphalt mixes. MPC report. University of Wyoming, WY, 2001.

[8] Majidzahed K, Brovold FN. Effect of water on bitumen-aggregate mixtures. Highway research board special report 98, 1968.

[9] Zvejnicks A. Progress with adhesion - improving bitumen additives. Highway Res Board Bull 1958;192:26-32.

[10] Petersen JC, Plancher HP, Harnsbergen M. Lime treatment of asphalt to reduce age hardening and improve flow properties. In: Proceedings, AAPT, vol. 56, 1987.

[11] Kennedy TW, Anagnos NJ. Lime treatment of asphalt mixtures, FHWA/TX-83/ 22+253-

4. Center for Transportation Research, The University of Texas at Austin, 1983. p. 20-8.

[12] National Lime Association. Lime the versatile chemical hydrated lime: a solution for high performance hot mix asphalt, fact sheet, 2003.

[13] Schmidt RJ. Graf PE. The effect of water on the resilient modulus of asphalttreated mixtures. In: Proceeding, Association of Asphalt Paving Technologists, vol. 41, 1972. p. $118-25$.

[14] Kennedy TW, Turnham N, Epps JA, Smoot CW, Young FM, Button JW. Evaluation of methods for field application of lime to asphalt concrete mixtures. In: Proceeding, Association of Asphalt Paving Technologists, vol. 52, 1983. p. 508-34.

[15] Kennedy TW. Use of hydrated lime in asphalt paving mixtures. Bulletin no. 325. National Lime Association, 1984.

[16] Tunnicliff, DG, Root RE. Introduction of lime into asphalt concrete mixtures. Interim guidelines. The Federal Highway Administration; 1984.

[17] Epps JE, Berger, JN. Anagnos, moisture sensitivity of asphalt pavements: a national seminar, California, 2003.

[18] National Lime Association. How to add hydrated lime to hot mix asphalt, fact sheet, 2003.

[19] Martin AE, Rand D, Weitzel D, Tedford D, Sebaaly P, Lane L, et al. Moisture sensitivity of asphalt pavements: a national seminar, 2003.

[20] Giovanni Polacco, Jiri Stastna, Dario Biondi, Federico Antonelli, Zora Vlachovicova and Ludovit Zanzotto. Rheology of asphalts modified with glycidylmethacrylate functionalized polymers. J.Coooid and Interface Science, 2004, 280,366-373.

[21] British Petrol. BP polymer modified bitumen-PMB facts. Report on PMB, 1997. 
[22] Kim YR, Lee HJ, Little DN. Fatigue characterization of asphalt concrete using viscoelasticity and continuum damage mechanics. J AAPT 1997; 66: 520-49.

[23] Kumar P, Chandra S, Bose S. Strength characteristics of polymer modified mixes. Int J Pave Eng 2006;7(1):63-71.

[24] Stuart KD, Youtcheff JS, Mogawer WS. Understanding the performance of modified asphalt binders in mixtures: evaluation of moisture sensitivity, FHWA-RD-02-029. Federal Highway Administration Turner-Fairbank Highway Research Center, 2001.

[25] Guian Wen, Yong Zhang, Yinxi Zhang, Kang Sun, Yongzhong Fan. Rheological characterization of storage-stable SBS-modified asphalts. J. polymer testing, 2002, 21,295302.

[26] Hailong Jin, Guangtao Gao, Yong Zhang, Yinxi Zhang, Kang Sun. Improved properties of polystyrene-modified asphalt through dynamic vulcanization. J. polymer testing, 2002, 21, 633-640.

[27] V. S. Punith, A. Veeraragavan. Behavior of Asphalt Concrete Mixtures with Reclaimed Polyethylene as Additive. J. Mater. Civ. Eng., 2007, 19(6), 500-507.

[28] Bradley, J. Putman, and Serji, N. Amirkhanian. Utilization of waste fibers in stone matrix asphalt mixtures. J. Resources Conservation and Recycling, 2004, 42,265-274.

[29] Brown ER, Cooley, LA. Designing stone matrix asphalt mixtures for rut- resistant pavements. National Cooperative Highway Research Program. Transportation Research Board. National Research Council. Washington DC USA, Report No. 425; 1999.

[30] American Society for Testing and Materials (ASTM). Standard Specification, Section 4, vol. $04-03 ; 2002$.

The work was carried out at the college of Engineering. University of Mosul 